\title{
Frequency of Modifiable Cardiovascular Risk Factors Such as Obesity, Diabetes Mellitus and Hypertension in a Benin Rural Area
}

\author{
Djimon Marcel Zannou1*, Anthelme Kouessi Agbodande1, Angèle Azon-Kouanou ${ }^{1}$, \\ Finagnon Armand Wanvoegbe ${ }^{2}$, Léopold Codjo 3 , Albert Dovonou ${ }^{3}$, \\ Dédé Priscillia Tatiana Baglo1, Fabien Houngbe ${ }^{1}$ \\ ${ }^{1}$ National Teaching Hospital-HKM of Cotonou, University of Abomey-Calavi, Abomey-Calavi, Benin \\ ${ }^{2}$ Departmental Hospital of Oueme-Plateau (Oueme Plateau), University of Abomey-Calavi, Abomey-Calavi, Benin \\ ${ }^{3}$ Departmental Hospital of Borgou-Alibori, University of Parakou, Parakou, Benin \\ Email: *djmzannou@yahoo.fr, agbotem@yahoo.fr, angele.azonkouanou@gmail.com, wafinarm@yahoo.fr, \\ leostelles@yahoo.fr, dovcom1@yahoo.fr, tatianabag@yahoo.fr, fab2012jos@yahoo.com
}

Received 13 August 2015; accepted 8 September 2015; published 11 September 2015

Copyright (C) 2015 by authors and Scientific Research Publishing Inc.

This work is licensed under the Creative Commons Attribution International License (CC BY).

http://creativecommons.org/licenses/by/4.0/

(c) (i) Open Access

\section{Abstract}

The fight against cardiovascular diseases requires the knowledge of their modifiable risk factors. This study aimed to assess the level of modifiable cardiovascular risk factors in a rural area in order to develop a prevention program. Methods: This is an analytical and cross-sectional study on data collected during a fairground medical consultation of adults from 20 to 25 May 2013, in both border districts of the municipality of Djidja (Agouna and Houto). The studied parameters were the capillary blood glucose profile, blood pressure profile, waist circumference (WC) and Body Mass Index (BMI). Diabetes is defined by a fasting blood glucose $\geq 1.26 \mathrm{~g} / \mathrm{L}$ two times. Hypertension is defined according to the criteria of JNC VII and obesity by BMI $\geq 30 \mathrm{~kg} / \mathrm{m}^{2}$; abdominal obesity is defined by a WC above $102 \mathrm{~cm}$ in men and $88 \mathrm{~cm}$ in women. Data were analyzed using SPSS software version 18.0. Results: A total of 926 people were included among whom $57.8 \%$ were women. The average age was $38.43 \pm 15.84$ years. The prevalence of diabetes mellitus was $2.9 \%$. The prevalence of obesity (BMI $\geq 30 \mathrm{~kg} / \mathrm{m}^{2}$ ) was $8.4 \% ; 10.8 \%$ of studied population had abdominal obesity and $19.2 \%$ had hypertension. Age above 35 years and obesity were significantly associated with hypertension. Risk factors of obesity (IMC $\geq 30 \mathrm{~kg} / \mathrm{m}^{2}$ ) were the place of residence (Agouna), the female gender, age between 35 and 64 and abdominal obesity. Conclusion: The frequency of cardiovascular risk factors, although small compared to the national level, remains a concern in the investigated rural communities. This must lead to undertake a survey on the lifestyle and dietary

\footnotetext{
"Corresponding author.
}

How to cite this paper: Zannou, D.M., Agbodande, A.K., Azon-Kouanou, A., Wanvoegbe, F.A., Codjo, L., Dovonou, A., Baglo, D.P.T. and Houngbe, F. (2015) Frequency of Modifiable Cardiovascular Risk Factors Such as Obesity, Diabetes Mellitus and Hypertension in a Benin Rural Area. Open Journal of Internal Medicine, 5, 50-57. 
habits of the inhabitants of these areas.

Keywords

Rural Area, Cardiovascular Risk Factors, Diabetes Mellitus, Hypertension, Obesity

\section{Introduction}

According to global status report on non communicable diseases in 2010, non-communicable diseases (NCDs) are the main causes of death all over the world, killing more people each year than any other causes combined. Contrary to the popular feeling, the available data show that nearly $80 \%$ of deaths from non-communicable diseases occur in low- and middle-income countries. Despite their rapid growth and inequitable distribution, much of the human and social impact caused each year by NCD-related deaths could be prevented through well understood, feasible and cost-effective interventions [1].

Beside, this report precises that among the 57 million deaths worldwide in 2008, $63 \%$ are due to non-communicable diseases, mainly cardiovascular diseases, diabetes, cancers and chronic respiratory diseases. However, cardiovascular diseases are the leading cause of death in the world (17 million per year) [1]. A significant action to prevent cardiovascular diseases could reduce mortality from NCDs.

The fight against cardiovascular diseases is done through the control of the variable cardiovascular risk factors (CVRF). These modifiable risk factors include behavioural risk factors (smoking, alcohol, physical inactivity and unhealthy diet) and bio-clinical risk factors (obesity, high blood pressure, diabetes mellitus and hypercholesterolemia).

The variable cardiovascular risk factors are likely to be urban areas diseases as cardiovascular diseases (CVD) are traditionally considered as those of civilization. Since the extent of CVRF is little-valued in rural areas, we want to study the frequency of some cardiovascular risk factors present in a rural area in order to develop a prevention program.

\section{Patients and Methods}

\subsection{Framework and Nature of the Study}

This is a descriptive cross-sectional study on data collected during a fairground medical consultation in both border rural districts of the municipality of Djidja (Agouna, Houto) from 20 to 25 May 2013. The municipality of Djidja is part of Zou area in the center of Benin. It shares a border with the Republic of Togo. The village of Houto is characterized by a predominantly rural population growing cereals and Agouna cropping patterns are more varied based on the production of tubers (yam).

According to the third general census of population and housing in 2002 (GCPH3), the number of people aged 15 and over is 5004 in the district of Agouna and 1942 in the one of Houto [2].

\subsection{Studied Population and Data Collection}

The studied population consists of people aged 15 and older, sick or not and residing in the districts of Houto or Agouna. All the residents of the area aged 15 and over were invited to the district's infirmary by a local crier's for a visit.

The age range over 15 years was chosen as corresponding to people usually admitted in Internal Medicine.

Medical consultations were performed by doctors of various specialties (general practitioners, cardiologists, internists, endocrinologists, neurologists). Biological tests were supervised by a biologist.

Each person admitted in consultation goes to the sorting station where socio-demographic's parameters, past medical history, complaints and constants such as blood pressure, weight, height, and waist circumference were recorded. Then the included subjects were admitted in the laboratory for the realization of fasting blood glucose (FBG) and in consultation where blood pressure is taken by the doctor before performing a clinical examination oriented according to the recorded complaints.

Only patients who had a health problem identified during the preliminary examinations as described above 
have been examined by specialist physicians.

Verbal consent of patients was obtained before inclusion.

\subsection{Studied Variables}

The variable cardiovascular risk factors studied were: diabetes, hypertension and obesity.

Socio-demographic characteristics studied were: age, sex, the district of origin.

Blood glucose was performed on a capillary sampling in the morning between 8 a.m. and 12 a.m., fasting blood glucose with the One Touch ${ }^{\circledR}$ Ultra 2. The blood pressure was taken in a sitting position after 15 min rest using OMNIRON ${ }^{\circledR}$ Blood Pressure Monitor. The weight was measured using SECA ${ }^{\circledR}$ scales. The size was measured using a wooden measuring rod. The waist circumference was measured with a tape measure with half-undressed people between the iliac crest and the last rib. The body mass index was calculated by the formula $\mathrm{W} / \mathrm{H}^{2}$ (W being the weight in $\mathrm{kg}$ and $\mathrm{H}$ is the height in meters).

The diabetes mellitus was defined by fasting blood glucose $\geq 1.26 \mathrm{~g} / \mathrm{L}$ twice, or a history of diabetes; impaired fasting glucose (IFG) as a fasting blood glucose $\geq 1.10 \mathrm{~g} / \mathrm{L}$ but $<1.26 \mathrm{~g} / \mathrm{L}$; hypertension was defined by the blood pressure higher or equal to $140 / 90 \mathrm{mmHg}$, or pre-hypertension. Were considered obese people with BMI $\geq 30 \mathrm{~kg} / \mathrm{m}^{2}$. Abdominal obesity was defined by US standards NCEP ATP III by waist circumference (WC) greater than $102 \mathrm{~cm}$ in men and greater than $88 \mathrm{~cm}$ in women [3].

\subsection{Statistical Analysis}

Data were entered and analyzed using SPSS 18.0 software. Categorical variables were expressed as a percentage and quantitative variables averaged together with a standard deviation.

The association between cardiovascular risk factors and socio-demographic characteristics was studied by calculating the Odd Ratio (OR) with $95 \%$ confidence interval.

We used the Chi-square test for the comparison of the percentages of Anova test for average comparisons. A $p$ value $<0.05$ was considered significant.

\section{Results}

\subsection{General Features}

In total, 926 people were included. Among them, 540 were from Agouna area and 386 from Houto.

883 subjects $(95.4 \%)$ had a rural activity based on agriculture.

The average age, weight, size and blood pressure were higher in included men than in women. The BMI was on average higher in women than in men. There was no significant difference in the abdominal perimeter average regardless of gender (Table 1 ).

The mean age was $38.4 \pm 16$, ranging from 15 to 95 years old.

The sex ratio was 0.7 .

Table 1. General characteristic of the studied population.

\begin{tabular}{ccccc}
\hline & Male & Female & Total & $p$ \\
\hline Number n (\%) & $391(42.2)$ & $535(57.8)$ & 926 & 0.049 \\
Age (years) & $39.6 \pm 15.8$ & $37.6 \pm 15.8$ & $38.4 \pm 15.8$ & 0.000 \\
Weight (kg) & $61.9 \pm 12.1$ & $58.0 \pm 14.1$ & $59.7 \pm 13.4$ & 0.000 \\
Size (cm) & $166.0 \pm 7.5$ & $156.0 \pm 6.6$ & $160.2 \pm 8.5$ & 0.000 \\
BMI (kg/m $\left.{ }^{2}\right)$ & $22.3 \pm 3.9$ & $23.7 \pm 5.4$ & $23.1 \pm 4.9$ & 0.343 \\
WC (cm) & $77.4 \pm 10.4$ & $78.1 \pm 11.1$ & $77.8 \pm 10.8$ & 0.021 \\
SBP (mmHg) & $126.7 \pm 19.8$ & $123.7 \pm 20.2$ & $125.0 \pm 20.1$ & $77.7 \pm 13.8$ \\
DBP (mmHg) & $78.4 \pm 14.1$ & $77.2 \pm 13.6$ & 0.199
\end{tabular}

BMI: body mass index; WC: waist circumference; SBP: systolic blood pressure; DBP: diastolic blood pressure. 


\subsection{Risk Factors}

\subsubsection{Frequencies}

Fasting blood glucose was performed in 276 people who had not eaten before the consultation. Diabetes was diagnosed in 8 people $(2.9 \%) ; 2$ of the latter were already aware of their condition. Impaired fasting glucose was found in $8.7 \%$ of subjects. The frequency of obesity, abdominal obesity and hypertension was respectively $8.4 \%$, $12.5 \%$ and $21.5 \%$ (Table 2).

\subsubsection{Associated Factors}

Among the studied factors (age, place of residence, sex, obesity or hypertension), none was significantly associated with the occurrence of diabetes $(p<0.05)$.

The analysis of the relationship between hypertension and other risk factors (Table 3) shows that hypertension was significantly associated with age, BMI and the presence of abdominal obesity.

According to Table 4, obesity defined by BMI was significantly related to place of residence (Agounna) and abdominal obesity. In addition, ages between 36 and 64 years and female gender are other risk factors for obesity (BMI) and abdominal obesity (Table 5).

Table 2. Prevalence of studied cardiovascular risk factors.

\begin{tabular}{|c|c|c|c|}
\hline & & Number & Percentage \\
\hline \multirow{3}{*}{$\begin{array}{c}\mathrm{FBG}(\mathrm{g} / \mathrm{L}) \\
\mathrm{N}=276\end{array}$} & $<1.10$ & 244 & 88.4 \\
\hline & $1.10-1.25$ & 24 & 8.7 \\
\hline & $\geq 1.26$ & 8 & 2.9 \\
\hline \multirow{3}{*}{$\begin{array}{c}\mathrm{BMI}\left(\mathrm{kg} / \mathrm{m}^{2}\right) \\
\mathrm{N}=926\end{array}$} & $<25.0$ & 695 & 75.1 \\
\hline & $25.0-29.9$ & 153 & 16.5 \\
\hline & $\geq 30.0$ & 78 & 8.4 \\
\hline \multirow{2}{*}{$\begin{array}{l}\text { Abdominal obesity } \\
\qquad \mathrm{N}=919\end{array}$} & Yes & 116 & 12.5 \\
\hline & No & 803 & 87.4 \\
\hline \multirow{2}{*}{$\begin{array}{l}\text { Hypertension } \\
\mathrm{N}=926\end{array}$} & Yes & 199 & 21.5 \\
\hline & No & 727 & 78.5 \\
\hline
\end{tabular}

BMI: body mass index; FBG: fasting blood glucose.

Table 3. Relationship between hypertension and other risk factors.

\begin{tabular}{|c|c|c|c|c|c|}
\hline & & \multicolumn{2}{|c|}{ Hypertension } & \multirow{2}{*}{ OR (IC 95\%) } & \multirow{2}{*}{$p$} \\
\hline & & Present & Absent & & \\
\hline \multirow{2}{*}{ Residence } & Houto & 78 & 308 & 1 & \multirow{2}{*}{0.235} \\
\hline & Agounna & 121 & 419 & $1.1(0.8-1.6)$ & \\
\hline \multirow{2}{*}{ Sex } & Male & 90 & 301 & 1 & \multirow{2}{*}{0.333} \\
\hline & Female & 109 & 426 & $0.9(0.6-1.2)$ & \\
\hline \multirow{3}{*}{ Age (years) } & $\leq 35$ & 48 & 452 & 1 & \multirow{4}{*}{$\begin{array}{l}0.000 \\
0.000\end{array}$} \\
\hline & $36-64$ & 130 & 237 & $5.2(3.6-7.5)$ & \\
\hline & $\geq 65$ & 21 & 38 & $5.2(2.8-9.6)$ & \\
\hline \multirow{3}{*}{$\operatorname{BMI}\left(\mathrm{kg} / \mathrm{m}^{2}\right)$} & $\leq 25$ & 115 & 580 & 1 & \\
\hline & $25-30$ & 53 & 100 & $2.7(1.8-3.9)$ & 0.000 \\
\hline & $\geq 30$ & 31 & 47 & $3.3(2.0-5.5)$ & 0.000 \\
\hline \multirow{2}{*}{ Abdominal obesity } & Absente & 150 & 653 & 1 & \multirow{2}{*}{0.000} \\
\hline & Present & 47 & 69 & $3.0(2.0-4.5)$ & \\
\hline \multirow{3}{*}{ FBG (g/L) } & $\leq 1.09$ & 66 & 178 & 1 & \\
\hline & $1.10-1.25$ & 6 & 18 & $0.9(0.3-2.4)$ & 0.829 \\
\hline & $\geq 1.26$ & 3 & 5 & $1.6(0.3-7.2)$ & 0.688 \\
\hline
\end{tabular}

BMI: Body Mass Index; FBG: fasting blood glucose. 
Table 4. Relationship between obesity (BMI) and other risk factors.

\begin{tabular}{|c|c|c|c|c|c|}
\hline & & \multicolumn{2}{|c|}{ Obesity in BMI $\left(\mathrm{kg} / \mathrm{m}^{2}\right)$} & \multirow{2}{*}{ OR (IC 95\%) } & \multirow{2}{*}{$p$} \\
\hline & & $\mathrm{BMI} \geq 30$ & $\mathrm{BMI}<30$ & & \\
\hline \multirow{2}{*}{ Residence } & Houto & 20 & 366 & 1 & \multirow{2}{*}{0.003} \\
\hline & Agounna & 58 & 482 & $2.2(1.3-3.7)$ & \\
\hline \multirow{2}{*}{ Sex } & Male & 19 & 372 & 1 & \multirow{2}{*}{0.001} \\
\hline & Female & 59 & 476 & $2.4(1.4-4.1)$ & \\
\hline \multirow{3}{*}{ Age (years) } & $\leq 35$ years & 27 & 473 & 1 & \\
\hline & $36-64$ & 47 & 320 & $2.6(1.6-4.2)$ & 0.000 \\
\hline & $\geq 65$ & 4 & 55 & $1.3(0.4-3.8)$ & 0.557 \\
\hline \multirow{2}{*}{ Abdominal obesity } & Absente & 16 & 787 & 1 & \multirow{2}{*}{0.000} \\
\hline & Present & 62 & 54 & $56.5(30.5-104.5)$ & \\
\hline \multirow{3}{*}{ FBG $(\mathrm{g} / \mathrm{L})$} & $\leq 1.09$ & 26 & 218 & 1 & \\
\hline & $1.10-1.25$ & 2 & 22 & $0.8(0.2-3.4)$ & 0.529 \\
\hline & $\geq 1.26$ & 1 & 7 & $1.2(0.1-10.1)$ & 0.602 \\
\hline
\end{tabular}

BMI: body mass index; FBG: fasting blood glucose.

Table 5. Relationship between abdominal obesity and other risk factors.

\begin{tabular}{|c|c|c|c|c|c|}
\hline & & \multicolumn{2}{|c|}{ Abdominal obesity } & \multirow{2}{*}{ OR (IC 95\%) } & \multirow{2}{*}{$p$} \\
\hline & & Present & Absent & & \\
\hline \multirow{2}{*}{ Residence } & Houto & 41 & 345 & 1 & \multirow{2}{*}{0.120} \\
\hline & Agounna & 75 & 458 & $1.4(0.9-2.1)$ & \\
\hline \multirow{2}{*}{ Sex } & Male & 15 & 374 & 1 & \multirow{2}{*}{0.000} \\
\hline & Female & 101 & 429 & $5.9(3.6-10.3)$ & \\
\hline \multirow{3}{*}{ Age (years) } & $\leq 35$ years & 46 & 449 & 1 & \multirow{4}{*}{0.837} \\
\hline & $36-64$ & 65 & 300 & $2.1(1.4-3.2)$ & \\
\hline & $\geq 65$ & 5 & 54 & $0.9(0.3-2.4)$ & \\
\hline \multirow{3}{*}{ FBG (g/L) } & $\leq 1.09$ & 34 & 207 & 1 & \\
\hline & $1.10-1.25$ & 5 & 19 & $1.6(0.6-4.6)$ & 0.368 \\
\hline & $\geq 1.26$ & 2 & 6 & $2.0(0.4-10.5)$ & 0.325 \\
\hline
\end{tabular}

FBG: fasting blood glucose.

\section{Discussion}

In the study, the recruitment of the subjects was carried out on a voluntary basis. This method could be a bias, because in the absence of chance factor, people who have decided to come and consult may have a special feature that motivates them. However, the involvement of local authorities and community volunteers allowed having a large number of people. The study had indeed included more than $1 / 10$ th of the population over 15 years who live in the area [2].

Moreover, few people were seen with an empty stomach. It explains that fasting blood glucose was performed in only 276 people.

The last failure of this study is the limited number of risk factors studied. Risk factors such as smoking, 
physical inactivity and hypercholesterolemia have not been studied. Smoking and physical inactivity were sought only in patients who had been examined by doctors as having a health problem identified during the preliminary examinations. They cannot be extrapolated to all subjects; then they were excluded from the studied variables. The cholesterol level has not been achieved because the study was conducted in enclave villages where the lab was not equipped for this blood test.

The average age of the subjects included was 38.4 years. The average age is inferior to the 43.4 reported in 2013 by Pessinaba S. and al in Senegal in a prevalence study of cardiovascular risk factors in the general population [4]. In Benin, Houinato DS and al. had reported an average age of 42.7 years [5]. The sex ratio shows a quite predominance of female gender. The female predominance is similar to that of the overall population structure of Zou area regarding the data from the third general census of population and housing, which shows a sex ratio of $88.9 \%$. This illustrates the representativeness of the studied sample [2]. Houinato DS and al observed in their study, a slight male predominance, while Pessinaba et al. observed like us, a female one [4] [5].

Men are on average older than women. This distribution does not reflect the trend in the 3rd census of the general population of Benin [6].

The frequency of diabetes in the studied population was $2.9 \%$. This rate is lower than the $4.6 \%$ reported by Djrolo in Cotonou, Benin, and 10.4\% reported by Pessinaba in Senegal [4] [7]. The prevalence we have observed is equivalent to 2.9\% reported by Silva-Matos and al in Mozambique in 2011; Silva-Matos and al have also observed a higher prevalence of diabetes in urban areas [8]. The difference in prevalence we observed with Djrolo in Benin could be explained by the difference in the studied population. Djrolo have mainly conducted their study in Cotonou, the economic capital city of Benin. This difference could also be related to different dietary habits between cities-dwellers and those in countryside (with a trend in our cities for the consumption of fatty and sugary foods), and physical inactivity, risk factors of obesity and thus of diabetes. The influence of dietary habits has not been highlighted in the comparison of the two rural communities (Houto and Agouna) having different agricultural production. However, obesity, diabetes's risk factors seems to besignificantly associated with fact of living in Agouna, which is area where tubers were predominantly cultivated $(p=0.000)$.

In our study, the prevalence of the obesity was $8.4 \%$, which is quietly inferior to the $23 \%$ observed by Pessinaba in Senegal. This significant difference can sharply illustrate the difference in the prevalence of diabetes between both studies. In the process, the prevalence of abdominal obesity that we have observed was relatively lower than the one reported by most authors [4] [5] [9]. Obesity and abdominal obesity are the mostly part of the metabolic syndrome of which we know the obvious link with diabetes [10].

The physiopathology of diabetes type 2 in the obese persons put several mechanisms at stake including the notion of insulin-resistence caused by obesity. Obesity is the primary factor in the definition of the metabolic syndrome, contributing to hyperglycaemia, hypertension and hypercholesterolemia [11]. According to Borys, abdominal obesity is an important indicator of metabolic deterioration, diabetogenic and atherogenic: insulin resistance, hyper-insulinemia, glucose intolerance, hyperglycaemia, hypertriglyceridemia, high concentration of ApoB, excess of low density LDL cholesterol, low levels of HDL cholesterol [12].

In our study, obesity was significantly associated with age and female gender. Didier Yves and Rival Junquero emphasize the link of metabolic syndrome with age but have not reported any predominance in female gender [13].

The hypertension was observed in our study in $21.5 \%$ of the studied population. This prevalence is lower than the $27.8 \%$ observed by Houinato throughout Benin in 2008 [5]. However, this prevalence is closer to the $23.3 \%$ found by Houinato in Zou area where our study was carried out. The prevalence that we have recorded is lower than the $46 \%$ observed by Pessinaba in Saint Louis (Senegal); in the latter case, the difference in observed prevalence seems mainly related to the population in consideration (urban in Saint Louis, Senegal) but also to the higher prevalence of obesity and diabetes in the population studied by Pessinaba [4]. In fact, obesity and diabetes increase the risk of hypertension [14].

In the studies conducted in rural areas, most authors have observed similar prevalence of hypertension to ours or even lower. This is the case of Hendriks who put much emphasison the difference in prevalence between rural and urban areas [15]. In Uganda rural area, Kotwani has reported prevalence of 14.6\%, lower than ours, while they have included subjects aged 18 and over [16]. However, our results are lower than the $44.7 \%$ reported by Williams in rural areas in Ghana; this difference is partly due to the inclusion by the authors of an older population they study (35 and over) [9]. In our study, in fact, hypertension was significantly associated with age. According to several authors, age appears to be an important risk factor for high blood pressure [17] [18]. This link 
between age and hypertension is largely related to atherosclerosis.

\section{Conclusion}

Cardiovascular risk factors such as obesity, abdominal obesity, diabetes and high blood pressure, though lower compared to the national level, remain a concern in the rural areas of the municipality of Djidja. From these factors, hypertension has the highest prevalence. This should inspire to undertake a survey on the lifestyle and dietary habits of the inhabitants of these localities to identify the key master to reduce these risk factors.

\section{Acknowledgements}

The authors thank the "Agence Béninoise de Gestion Intégrée des Espaces Frontaliers, ABéGIEF" (Beninese Agency for Integrated Management of Benin borders) for its support in carrying out this study.

\section{References}

[1] World Health Organization (2010) Global Status Report on Noncommunicable Diseases 2010. WHO Library Cataloguing-in-Publication Data, $176 \mathrm{p}$.

[2] National Institute of Statistics and Economic Analysis (2004) Specifications Villages and City Districts Department ZOU. Demographic Studies Department, Cotonou, 29 p.

[3] Expert Panel on Detection, Evaluation, and Treatment of High Blood Cholesterol in Adults (2001) Executive Summary of the Third Report of the National Cholesterol Education Program (NCEP) Expert Panel on Detection, Evaluation, and Treatment of High Blood Cholesterol in Adults (Adult Treatment Panel III). JAMA, 285, 2486-2497. http://dx.doi.org/10.1001/jama.285.19.2486

[4] Pessinaba, S., Mbayea, A., Yabéta, G.A.D., Harouna, H., Sib, A.E., Kane, A.D., et al. (2013) Prevalence Survey of Cardiovascular Risk Factors in the General Population in St. Louis (Senegal). Annales de Cardiologie et d'Angéiologie, 62, 253-258. http://dx.doi.org/10.1016/j.ancard.2013.02.005

[5] Houinato, D.S., Gbary, A.R., Houehanou, Y.C., Djrolo, F., Amoussou, M., Segnon-Agueh, J., et al. (2012) Prevalence of Hypertension and Associated Risk Factors in Benin. Revue d Épidémiologie et de Santé Publique, 60, 95-102. http://dx.doi.org/10.1016/j.respe.2011.09.010

[6] National Institute of Statistics and the Economic Analysis (2003) Third General Census of Population and Housing: Brief Summary of the Analysis. Demographic Studies Branch, Cotonou, $48 \mathrm{p}$.

[7] Djrolo, F., Houinato, D., Gbary, A., Akoha, R., Djigbénoudé, O. and Sègnon, J. (2012) Prevalence of Diabetes Mellitus in the Adult Population in Cotonou, Benin. Médecine des maladies Métaboliques, 6, 167-169. http://dx.doi.org/10.1016/S1957-2557(12)70386-3

[8] Silva-Matos, C., Gomes, A., Azevedo, A., Damasceno, A., Prista, A. and Lunet, N. (2011) Diabetes in Mozambique: Prevalence, Management and Healthcare Challenges. Diabetes \& Metabolism, 37, 237-244. http://dx.doi.org/10.1016/j.diabet.2010.10.006

[9] Williamsa, E.A., Keenan, K.E., Ansong, D., Simpson, L.M., Boakye, I., Boaheng, J.M., et al. (2013) The Burden and Correlates of Hypertension in Rural Ghana: A Cross-Sectional Study. Diabetes \& Metabolic Syndrome, 7, $123-128$.

[10] Florez, H., Palacio, A. and Tamariz, L. (2008) Syndrome métabolique, diabète et maladies cardiovasculaires: Un lien avéré. Diabètes Voice, 53, 21-24.

[11] Standl, E. (2005) Aetiology and Consequences of the Metabolic Syndrome. European Heart Journal, 7, D10-D13. http://dx.doi.org/10.1093/eurheartj/sui023

[12] Borys, J.M. and Dievart, F. (2006) Abdominal Obesity. Les cahiers de formation continue du quotidien du pharmacien, cahier 2, 1-15.

[13] Junquero, D. and Rival, Y. (2005) Metabolic Syndrome: What Definition for What Treatment(s)? Medecine/Sciences, 21, 1045-1053. http://dx.doi.org/10.1051/medsci/200521121045

[14] Ntyonga-Pono, M.P. (1996) Hypertension in Gabonese Diabetic. Médecined' Afrique Noire, 43, 434-437.

[15] Hendriks, M.E., Wit, F.W.N.M., Roos, M.T.L., Brewster, L.M., Akande, T.M., de Beer, I.H., et al. (2012) Hypertension in Sub-Saharan Africa: Cross-Sectional Surveys in Four Rural and Urban Communities. PLoS ONE, 7, e32638. http://dx.doi.org/10.1371/journal.pone.0032638

[16] Kotwani, P., Kwarisiima, D., Clark, T.D., Kabami, J., Geng, E.H. and Jain, V. (2013) Epidemiology and Awareness of Hypertension in Arural Ugandan Community: A Cross-Sectional Study. BMC Public Health, 13, 1151.

http://dx.doi.org/10.1186/1471-2458-13-1151 
[17] Kunutsor, S. and Powles, J. (2009) Descriptive Epidemiology of Blood Pressure in a Rural Adult Population in Northern Ghana. Rural and Remote Health, 9, 1095. http://www.rrh.org.au

[18] Howard, B.V., Lee, E.T., Yeh, J.L., Go, O., Fabsitz, R.R., Devereux, R.B., et al. (1996) Hypertension in Adult American Indians: The Strong Heart Study. Hypertension, 28, 256-264. http://dx.doi.org/10.1161/01.HYP.28.2.256 